Journal of Extension Education

Vol. 29 No. 2, 2017

DOI:https://doi.org/10.26725/JEE.2017.2.29.5850-5856

\title{
Perception of Farmers on Usefulness of Mobile Service in Manipur
}

\section{Santha Govind ${ }^{1}$, M. Kavaskar ${ }^{2}$ and Ajoickam Christina ${ }^{3}$}

\begin{abstract}
The revolution in mobile communication is providing a lifeline to agricultural communities around the developing world. Mobile phones significantly reduce communication and information costs. Mobile phones also provide new opportunities for farmers to obtain access to agricultural information, such as market prices, weather report, and agricultural techniques in various formats. Hence, keeping this in mind, a study was taken up to assess the perception of respondents on the usefulness of technologies transferred through mobile service functioning in Bishnupur District of Manipur. A sample of 120 registered farmers belonging to Intelligent Advisory Service for Farmers (IASF) mobile service was selected by using proportionate random sampling technique. Data were collected with the help of a well structured and pre tested interview schedule. The data collected were scored, tabulated and analyzed using appropriate statistical tools. The findings on respondents' perception on usefulness of mobile service showed that most of the respondents expressed that they were satisfied with the language used by the IASF mobile service in transferring the information.
\end{abstract}

Keywords : Mobile service; SMS; Perception; Paddy farmer; Manipur

\section{INTRODUCTION}

Today, in India, mobile phones are being used by farmers, not only as a person to person voice communication medium, but also, to provide access to information through short message service (SMS), multimedia message service (MMS) and access to the internet.

Mobile phones significantly reduce communication and information costs. Poor communication facilities lead to limited access to information and this can lead to loss of income. Mobile phones also provide new opportunities for farmers to obtain access to agricultural information, such as market prices, weather report, agricultural techniques in various formats like audio (voice), videos (internet) and text (SMS). The revolution in mobile communication has already begun to benefit farmers, even in remote regions of the world. Mobile services are at work in the field of agriculture, mostly

1.Professor, 2. Asst.Professor, \& 3- PG Scholar, Dept. of Agrl.Extension, Faculty of Agriculture, Annamalai University, Annamalai Nagar, 608002 
for sharing and obtaining information. Across the developing world, there are programmes that give farmers access to research and best practices, weather information and market prices via SMS, Interactive Voice Response (IVR) or call centres.

Hence, keeping this in mind, a study was taken up to assess the extent of utilization of information disseminated through mobile service.

\section{METHODOLOGY}

The study was taken up to assess the extent of usefulness of information disseminated through mobile service. The present study was conducted in Bishnupur District of Manipur state during 2015. The study was taken up in four villages of Bishnupur block which were selected based on the highest number of registered farmers under Intelligent Advisory Service for Farmers (IASF). A sample of 120 registered farmers under IASF mobile service was selected by using proportionate random sampling technique. Data were collected with the help of a well structured and pre tested interview schedule. The data collected were scored, tabulated and analyzed using statistical tools viz., percentage analysis, cumulative frequency method.

Perception in the study referred to the extent to which the respondent perceived the information communicated through the mobile service as useful or otherwise. The selected subject matter, paddy and other general information was included in consultation with the co-ordinator of IASF, subject matter specialists and other NGO personnel involved in IASF mobile service. Perceived usefulness of information through mobile service was measured under two dimensions viz., 1.Recommended technologies were useful and 2. Not useful. Further, their perception on mobile service was also assessed against ten specific technologies and eight general items.

\section{FINDINGS AND DISCUSSION}

\section{Practice-wise Perception of the Respondents on the usefulness of recommended Paddy Technologies}

Majority (61.67\%) of the respondents had high level of perception on usefulness of recommended paddy technologies.

In order to have an in depth idea about the perception on the usefulness of the specific paddy technologies of the respondents, practice wise perception of respondents was worked out and the results are given in Table 1.

It could be observed from the data that out of ten paddy technologies, majority of the respondents $(90.00$ per cent) perceived the information on selection of varieties as useful followed by information on pest management $(76.68$ per cent) and nutrient management (63.33 per cent) as useful. The possible reason for better perception on selection of varieties, pest management and nutrient 
Table 1.

Distribution of Respondents according to their Practice-wise Perception on Usefulness of Recommended Paddy Technologies

\begin{tabular}{|c|l|c|c|}
\hline \multicolumn{1}{|c|}{ Subject Matter } & Number & Percentage \\
\hline 1. & Selection of varieties & 108 & 90.00 \\
\hline 2. & Time of sowing & 64 & 53.33 \\
\hline 3. & Nursery management & 56 & 46.66 \\
\hline 4. & Nutrient management & 76 & 63.33 \\
\hline 5. & Weed management & 76 & 63.33 \\
\hline 6. & Pest management & 92 & 76.68 \\
\hline 7. & Disease management & 72 & 60.00 \\
\hline 8. & Seed production technique & 40 & 33.33 \\
\hline 9. & Marketing information & 68 & 56.68 \\
\hline 10. & Post harvest management & 44 & 36.68 \\
\hline
\end{tabular}

management in paddy could be due to the regular use of mobile phones and also due to obtaining timely information for taking up the operations without delay. It could be observed from the same table, that all the four technologies viz., weed management (63.33 per cent), disease management (60.00 per cent), marketing information (56.68 per cent) and time of sowing (53.33 per cent) were perceived to be useful by majority of the respondents. The probable reason could be that the mobile service provides solution to all technical problems of farmers pertaining to weed management and disease management. Further, it also provides need based and timely information on marketing and time of sowing and there is no distortion of information provided through mobile service.
Further, it could be noticed from the same table, that a little less than fifty percent (46.66 per cent) of the respondents had perceived the information to be useful on nursery management (40.00 per cent) and post harvest management (36.68 per cent) to be useful. The reason could be that the information on nursery management and post harvest management is reaching the farmers in time. As majority of the farmers belonged to high level of innovativeness they were eager to get additional information. Further, the farmers might have felt that the information received through mobile was very clear, easily understandable and the information transferred through mobile service network as appropriate and reliable. 
Information on seed production technique(33.33 percent) was perceived as useful by less percentage of respondents. The possible reason may be some of the information relevant to utilization of seed production techniques at the field level is not being transferred through mobile service. It could be observed that almost two-fifths of the respondents (39.17 per cent) and medium level of perception on the usefulness of the recommended general information, followed by 35.00 per cent with high level and 25.83 per cent with low level of perception.

Practice-wise Perception of the Respondents on Usefulness of Recommended General Information

Eight practices were selected for assessing the perception of the respondents on the usefulness of recommended general information. Results regarding the practice wise perception of the respondents are furnished in Table 2 .

It could be observed from Table 2 that majority of the respondents $(70.00$ per cent) perceived the information on latest technologies in agriculture as useful followed by weather information $(66.68$ per cent) and information on training programmes (63.33 per cent). Due to the vagaries of monsoon, the farmers might have perceived the information about weather condition as more useful. Further, the information on government schemes and latest technologies are helpful for improving the livelihood of the farmers and hence the respondents might

Table 2.

Distribution of Respondents according to their Practice wise Perception on Usefulness of Recommended General Information

$(\mathrm{n}=120)$

\begin{tabular}{|c|l|c|c|}
\hline S1.No. & \multicolumn{1}{|c|}{ Subject Matter } & Number & Percentage \\
\hline 1. & Latest technologies in agriculture & 84 & 70.00 \\
\hline 2. & Information on government schemes & 60 & 50.00 \\
\hline 3. & Information on training programmes & 76 & 63.33 \\
\hline 4. & Availability of agricultural inputs & 32 & 26.68 \\
\hline 5. & Weather information & 80 & 66.68 \\
\hline 6. & Crop insurance & 24 & 20.00 \\
\hline 7. & Value addition & 68 & 27.50 \\
\hline 8. & $\begin{array}{l}\text { Marketing information on other } \\
\text { commodities }\end{array}$ & & 56.68 \\
\hline
\end{tabular}


have felt that the information provided on these technologies was reliable and accurate.

Further, it could be seen from the same table, that majority of the respondents (56.68 per cent) had perceived the information on marketing information on other commodities as useful followed by information on government schemes (50.00 per cent). Most of them might have utilized the information on these technologies. Hence, the respondents would have perceived these technologies as useful.

A little more than one-fourth (27.50 per cent) of the respondents perceived the information on value addition and availability of agricultural inputs (26.68 per cent) as useful. Further, only 20.00 per cent of the respondents perceived the information on crop insurance as useful. It may be due to lack of knowledge and awareness on these technologies.

\section{Perception on Usefulness of Mobile service}

The results on distribution of respondents according to their perception on usefulness of mobile service are given in Table 3.

\section{Preferred Language}

Most of the respondents (95.00 per cent) expressed that they are satisfied with the local language used by the IASF mobile service in transferring the information. This finding is in line with the findings of Zanello (2011).

Table 3.

\section{Distribution of Respondents According to their Perception on} Usefulness of Mobile service

$(\mathrm{n}=120)$

\begin{tabular}{|c|l|c|c|}
\hline S1.No. & \multicolumn{1}{|c|}{ Statement } & Number & Percentage \\
\hline 1. & Accuracy of information & 72 & 60.00 \\
\hline 2. & Reliable & 78 & 65.00 \\
\hline 3. & Provides complete information & 30 & 25.00 \\
\hline 4. & Motivate to adopt & 80 & 66.67 \\
\hline 5. & Message is understandable & 90 & 75.00 \\
\hline 6. & Use of simple words and sentences & 69 & 57.50 \\
\hline 7. & Increase productivity & 100 & 83.33 \\
\hline 8. & Solve farmers' problems & 94 & 78.33 \\
\hline 9. & Knowledge gained & 77 & 64.16 \\
\hline 10. & Saves time and cost & 90 & 75.00 \\
\hline 11. & Preferred language & 114 & 95.00 \\
\hline
\end{tabular}




\section{Increase Productivity}

Almost all the respondents $(83.33$ per cent) agreed that the information transmitted through mobile service increased their productivity. This finding is in line with the findings of Rizvi (2010).

\section{Solve Farmers' Problems}

Nearly eighty per cent (78.33 per cent) of the respondents opined that the IASF mobile service could solve farmers' problems by means of providing meaningful information on specific problems. In the IASF mobile service, the information right from the selection of seed to post harvest management are updated regularly and comprehensive in nature. This finding is in line with the findings of Kennedy (2013).

\section{Message is Understandable}

A vast majority $(75.00$ per cent) of the respondents reported that the information was under with the understandable. This might be due to the fact that IASF mobile service contained sequential presentation of message or information in simple sentences and in local dialect. This finding is in line with the findings of Aker and Mbiti (2010).

\section{Provides Complete Information}

Only one-fourth (25.00 per cent) of the respondents stated that the information provided was complete. This finding is in line with the findings of Jagun et al. (2007).

\section{CONCLUSION}

Medium to high level of perception on usefulness of paddy technologies was observed among majority of the respondents. Hence, the organisations concerned with transferring agriculture and allied technologies through mobile service need to realise the potential of mobile service for the speedy dissemination of information to farmers.

Further, the findings on perception on usefulness of few paddy technologies viz., nursery management, post harvest management and seed production technique was found to be low. With respect to the findings on perception on mobile service, three-fourths of the respondents expressed that the information was incomplete.

Hence, efforts should be made to disseminate complete and precise information on all aspects of crop and related information for harnessing the possibilities of utilizing the information, The mobile service authorities need to take extra care to streamline the system so as to prepare relevant content for maximum utility by the end users.

\section{REFERENCES}

Aker, J.C \& Mbiti, I. (2010). Information from markets near and far : Mobile phones and agricultural markets in Niger, American Economic Journal of Applied Economics, 2 : 46-59.

Aloyce, M. (2005). CT for improved crop 
marketing in rural Tanzania: Project Summary: 1-30.

Jagun, A., Herks, R \& Whalley, J. (2007). Mobile telephony and developing country micro-enterprise: A Nigerian Case Study, Institute for Development Policy and Management. Available at www.sed.manchester.ac.uk.

Kennedy, P. (2013). IC and farming information: An evaluation of institutions and users' perception in Andhra Pradesh, American Journal of Research in Humanities, Arts and Social Sciences, 13(364): 142-147.

Mittal, S., Gandhi, S \& Tripathi, G. (2008). Role of mobile phone technology in improving small farm productivity, Economic Survey, Ministry of Finance, Government of India.

Rizvi, S.M.H. (2010). Livelihood solutions through mobile technology: An assessment, Institute of Rural Research and Development, Technical Paper No. 1: 1-70.

Zanello, G. (2011). Does the use of mobile phone reduce transactions costs and enhance participation in agricultural markets? Household evidence from Northern Ghana, CSAE Conference 2011, Economic Development in Africa: (1)23. 